\title{
Congenital pituitary stalk interruption syndrome with isolated GH and TSH deficiency and Rathke's cleft cyst - an incidental association
}

\author{
Wessling A. ${ }^{1}$, Paixão R. ${ }^{1}$, Aragüés J.M. ${ }^{1}$, Mascarenhas M. ${ }^{1}$
}

INTRODUCTION

${ }^{1}$ Endocrinology Department of Santa Maria University Hospital, Lisbon, Portugal

- Congenital pituitary stalk interruption syndrome (PSIS) is a rare condition, characterized by the triad (not always complete) of absence/hypoplasia of the pituitary stalk, hypoplasia/aplasia of the anterior pituitary and absence or ectopy of the posterior pituitary high signal intensity, on Magnetic Resonance Imaging (MRI). It implies a permanent growth hormone (GH) deficiency, in $77 \%$ associated with other pituitary hormones deficiencies. It's exact etiology remains unknown; mutations in HESX1 and LHX4 genes have been associated, but in most cases no genetic cause is found.

- Rathke's cleft cysts (RCC) present typically as intrasellar and/or suprasellar benign cystic lesions, formed from remnants of the embryologic Rathke's pouch, the most common incidentally discovered sellar lesions (ranging from few mm to $2 \mathrm{~cm}$ diameter), with a female/male ratio of $1: 3$ and a higher incidence between the $4^{\text {th }}$ and $6^{\text {th }}$ decades. Symptomatic cases are rare and associated with pressure effects to adjacent structures.

\section{CLINICAL CASE}

- A 18 year-old boy was referred from the Pediatric Endocrinology Department, with the diagnosis of GH deficiency and central hypothyroidism $(\mathrm{CH})$ since the age of 9. Spinal scoliosis was simultaneously diagnosed and he started proper follow up. MRI at diagnosis revealed a small pituitary gland, absence of posterior pituitary bright spot, pituitary stalk atrophy and a small pineal cyst.

- Therapy with levothyroxine (50 $\mu \mathrm{g} /$ day) and recombinant( $r) \mathrm{GH}(20 \mu \mathrm{g} / \mathrm{kg} / \mathrm{d})$ was initiated after diagnosis. He had a normal puberty development starting at the age of 12 . The scoliosis worsened, needing spinal surgery and $\mathrm{rGH}$ was suspended at 16,7 years, with the final target height of $170,8 \mathrm{~cm}$.

- When referred to the Adult Endocrinology Department, he was only medicated with levothyroxine $100 \mu \mathrm{g} /$ day. Reevaluation showed no other pituitary hormone deficiencies and he had no symptoms of diabetes insipidus. At the age of 23 brain RMI was repeated, which showed a $7 \mathrm{~mm}$ sellar and suprasellar cystic lesion, suggestive of RCC causing pituitary compression, pituitary stalk hypoplasia and absence of the posterior pituitary bright spot in T1 (Figure 1). In the follow up, until now, at the age of 24 , his condition remains stable.
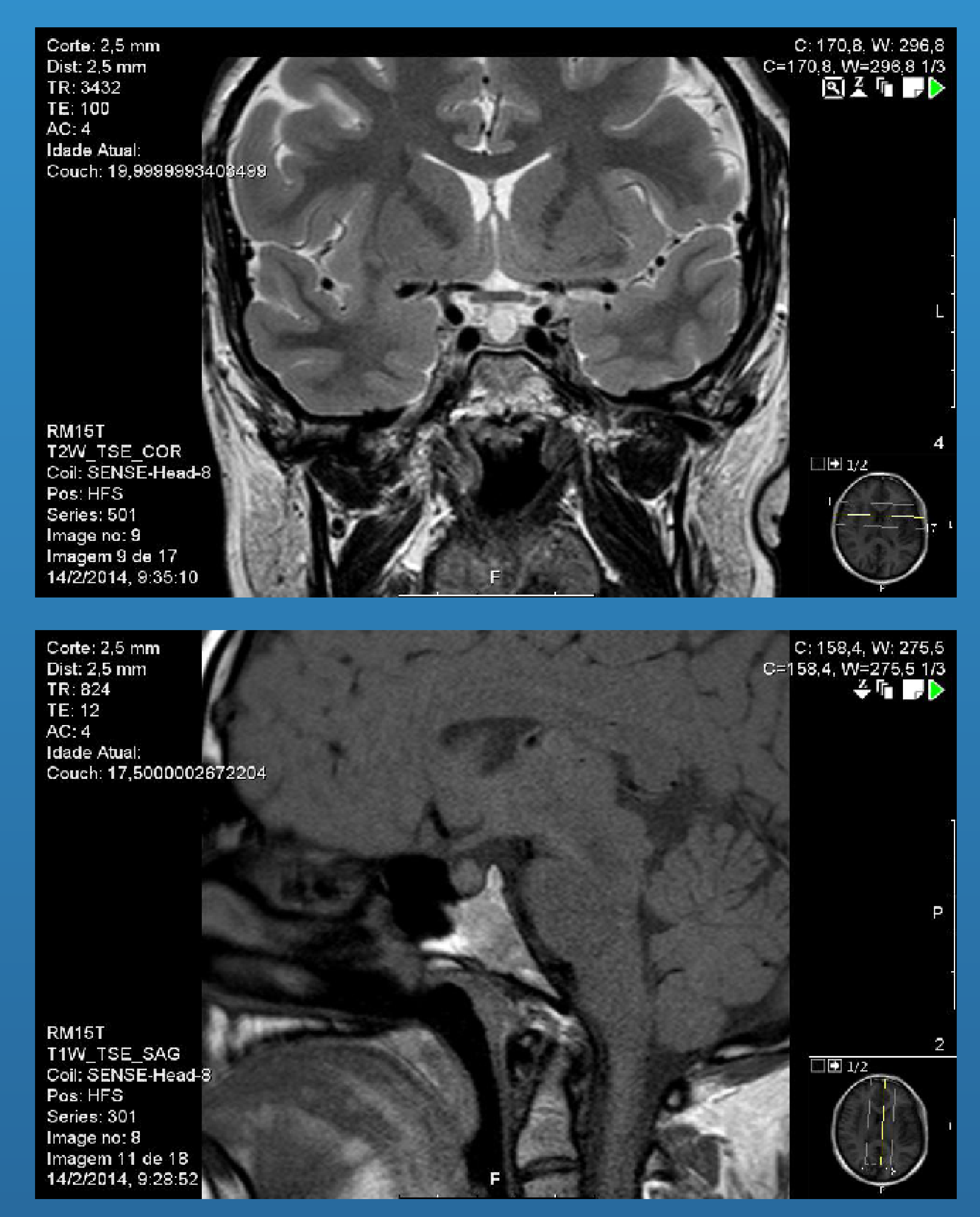

Fig. 1 - Reevaluation MRI at 23 years showing a sellar and suprasellar cystic lesion with pituitary compression, pituitatry stalk hypoplasia and absence
of posterior pituitary bright spot

\section{CONCLUSIONS}

- In this clinical case, a patient with PSIS had a RCC incidentally diagnosed in a follow up MRI. Association between tese two entities is uncommon, although co-existence of RCCs with pituitary adenomas has been reported.

- After diagnosis of PSIS, it is crucial to evaluate if GH deficiency is isolated or associated with other pituitary hormone deficiencies. The exact mechanism by which a hypopituitarism develops slowly remains controversial. In most cases, GH insufficiency develops first, probably because GRH-containing neurons in the arcuate nuclei are the most likely to be affected by stalk abnormalities. In this case bowth hormone deficiencies were diagnosed simultaneousy.

- Natural history of RCC is not clear, but they seem to grow slowly with time, with a low prevalence in paediatric populations, increasing with age. This patient was diagnosed incidentally still at an earlier age and, although he presented pituitary compression there was no worsening of the pituitary function. However follow up must be kept.

- Genetic tests results are pending.

References

• Brauner Pr Raja. Pituitary Stalk interruption syndrome. Disponivel em: http://www.orpha.net/. Acesso em 26/01/2015

- Kullarni C, Moorthy S, Pullara S, Rajeshkannan R, Unnikrishan A. Pituitary stalk transection: comparison of clinico-radiological fe

-Han SJ, Rolston JD, Jahangiri A, Aghi MK. Rathke's cleft cysts: review of natural history and surgical outcomes. J. Neu

-Delman BN. Imaging of pediatric pituitary abnormalities. Endocrinol Metab Clin N Am. 2009; 38: 673-698 